$06.1 ; 06.4 ; 12.1$

\title{
Возможность синтеза наноразмерного карбида молибдена в атмосферной электроразрядной плазме
}

\author{
(C) А.Я. Пак \\ Национальный исследовательский Томский политехнический университет, Томск, Россия \\ E-mail: ayapak@tpu.ru
}

Поступило в Редакцию 14 мая 2019г.

В окончательной редакции 14 мая 2019г.

Принято к публикации 20 мая 2019 г.

\begin{abstract}
Изложены результаты экспериментальных исследований, свидетельствующие о возможности получения кристаллических фаз карбида молибдена в плазме дугового разряда постоянного тока, инициированного внутри полого графитового катода в воздушной газовой среде при нормальных атмосферных условиях. По данным рентгеновской дифрактометрии в порошковом продукте синтеза идентифицируются две фазы карбида молибдена: $\mathrm{Mo}_{1.2} \mathrm{C}_{0.8}$ и $\mathrm{Mo}_{2} \mathrm{C}$, а также графит и металлический молибден. По данным просвечивающей электронной микроскопии частицы карбида молибдена находятся в углеродной матрице и характеризуются размерами, преимущественно не превышающими $5-10 \mathrm{~nm}$.
\end{abstract}

Ключевые слова: карбид молибдена, электродуговой синтез, безвакуумный метод.

DOI: 10.21883/PJTF.2019.17.48217.17877

Карбиды молибдена характеризуются комплексом важных для науки и техники свойств: высокая твердость, износостойкость, коррозионная стойкость, относительно высокая электропроводность и теплопроводность, каталитическая активность, сравнимая с таковой для металлов платиновой группы [1,2]. Комплекс свойств карбидов молибдена позволяет заменить ими металлы платиновой группы в ряде технологий [3], в частности в процессах производства водорода, а именно в составе катализаторов [4]. Получают порошковые материалы на основе карбида молибдена с помощью различных методик, в том числе электродуговых $[5,6]$. В настоящей работе представлены результаты экспериментальных исследований, свидетельствующие о возможности получения кристаллических фаз карбида молибдена в плазме дугового разряда постоянного тока, инициированного в разрядном промежутке между графитовыми электродами, расположенными в открытой воздушной среде. Реализуемый в воздушной среде пониженного и нормального давления электродуговой метод в последние годы активно применяется для получения углеродных наноструктур [7,8], некоторых карбидов [9]. При этом сведений об успешном синтезе карбида молибдена в плазме дугового разряда постоянного тока, инициированного в открытой воздушной среде нормального давления, в научной литературе не обнаружено.

Экспериментальные исследования проводились на лабораторном электродуговом стенде. Графитовые анод и катод подключаются к источнику постоянного тока. Анод выполнен в виде сплошного цилиндра, катод - в виде тигля, на дно которого помещается исходная порошковая смесь ультрадисперсного графита и молибдена в различных массовых соотношениях $(\mathrm{Mo} / \mathrm{C}=3 / 1,1 / 1,1 / 3,1 / 6)$ в количестве $0.50 \pm 0.05 \mathrm{~g}$.
Дно катода, покрытое смесью исходных реагентов, и торец анода образуют разрядный промежуток, величина которого непосредственно после инициирования дуги устанавливается в пределах $0.5 \pm 0.1 \mathrm{~mm}$. Сила тока контролируется широтно-импульсным модулятором в составе выпрямительно-инверторного модуля силового источника питания. В рассматриваемой серии экспериментов предварительно устанавливалось значение силы тока, равное $165 \mathrm{~A}$; разряд поддерживался в течение $10.0 \pm 0.2 \mathrm{~s}$ в каждом эксперименте. Ток разрядного контура и напряжение на дуговом разряде измерялись цифровым двухканальным осциллографом Rigol DS1052E (50 MHz) при помощи датчика тока Honeywell CSLA2DJ и стандартного делителя напряжения (10:1). По полученным осциллограммам тока и напряжения рассчитывалась электрическая мощность разряда, а также количество подведенной энергии.

Полученный порошковый продукт электродугового синтеза собирался с внутренней поверхности тигля катода - и анализировался методами рентгеновской дифрактометрии (Shimadzu XRD7000s, $\mathrm{CuK}_{\alpha}$-излучение), растровой (Tescan Vega 3 SBU с энергодисперсионным анализатором Oxford X-Max-50) и просвечивающей (JEOL JEM 2100F) электронной микроскопии.

На рис. 1 представлены рентгеновские дифрактограммы типичного продукта электродугового синтеза, исходных порошков ультрадисперсного графита и кубической фазы молибдена. На дифрактограмме продукта синтеза идентифицируются максимумы, свидетельствующие о присутствии в составе продукта синтеза остатков исходных реагентов. Наиболее близкими кристаллическими фазами в пределах доступной базы структурных данных PDF4+ следует считать ICDD N 04-015-2407 (графит gC с параметрами решетки $a=2.4691 \AA, c=6.8669 \AA)$, 
Результаты расшифровки SAED (рис. 3) в сравнении с эталонами

\begin{tabular}{|c|c|c|c|c|}
\hline \multirow{2}{*}{$\begin{array}{l}\text { № } \\
\Pi / \Pi\end{array}$} & \multirow{2}{*}{$\begin{array}{c}d_{\exp }, \AA \\
(\text { рис. } 3)\end{array}$} & \multicolumn{3}{|c|}{$d_{\text {refer }}, \AA$} \\
\hline & & $(\mathrm{N} \mathrm{04-015-2407,} \mathrm{gC)}$ & $\left(\mathrm{N} \mathrm{04-016-3695,} \mathrm{Mo}_{2} \mathrm{C}\right)$ & $\left(\mathrm{N}\right.$ 04-006-2272, $\left.\mathrm{Mo}_{1.2} \mathrm{C}_{0.8}\right)$ \\
\hline 1 & 3.424 & 3.433 & - & - \\
\hline 2 & 2.529 & - & 2.605 & 2.571 \\
\hline 3 & 2.152 & 2.138 & 2.137 & 2.126 \\
\hline 4 & 2.097 & 2.042 & 1.970 & 1.949 \\
\hline 5 & 1.696 & 1.717 & 1.757 & 1.633 \\
\hline 6 & 1.556 & 1.562 & 1.533 & 1.508 \\
\hline 7 & 1.329 & 1.339 & 1.322 & 1.301 \\
\hline 8 & 1.263 & 1.235 & 1.271 & 1.262 \\
\hline 9 & 1.217 & - & 1.210 & 1.220 \\
\hline 10 & 1.183 & 1.161 & 1.189 & 1.186 \\
\hline
\end{tabular}

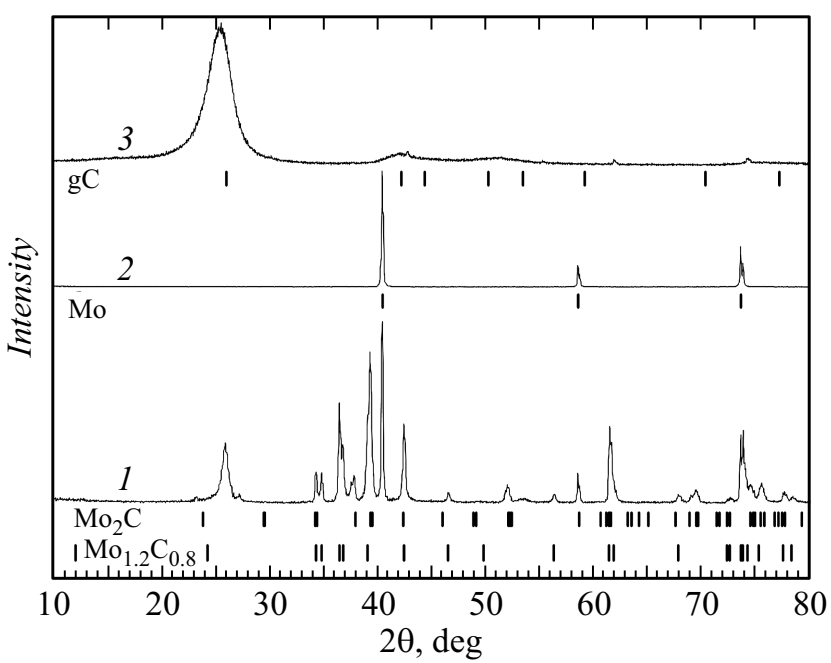

Рис. 1. Типичные рентгеновские дифрактограммы продукта синтеза (1) и исходных материалов $(2,3)$ в сравнении с эталонными данными.

ICDD N 01-077-8340 (молибден кубической модификации с параметром решетки $a=3.1490 \AA)$. Следует отметить наличие в базе данных множества близких карточек других фаз, незначительно различающихся с обозначенными эталонами (в пределах сотых долей ангстрема). Также на картине дифракции идентифицируется множество максимумов, соответствующих синтезированным кристаллическим фазам. В составе продукта идентифицировано две фазы карбида молибдена: орторомбическая модификация $\mathrm{Mo}_{2} \mathrm{C}$ (ICDD $\mathrm{N}$ 04-016-3695) с параметрами элементарной ячейки $a=4.7572 \AA, b=6.0169 \AA, c=5.2127 \AA$; гексагональный $\mathrm{Mo}_{1.2} \mathrm{C}_{0.8}$ (ICDD N 04-006-2272) с параметрами элементарной ячейки $a=3.0160 \AA, c=14.6400 \AA$. Совокупность обозначенных выше четырех кристаллических фаз позволяет идентифицировать практически все максимумы на картине рентгеновской дифракции, за исключением малоинтенсивных отражений около $2 \theta \sim 23$ и $\sim 27 \mathrm{deg}$, которые, вероятно, могут соответствовать следам оксида или оксинитрида молибдена либо иным примесям в незначительных количествах.

На рис. 2 приведена зависимость фазового состава продукта синтеза от массового соотношения $\mathrm{Mo} / \mathrm{C}$ в составе смеси исходных реагентов. Видно, что с увеличением доли углерода в исходной смеси до массового соотношения $\mathrm{Mo} / \mathrm{C}=1 / 6$ можно добиться практически нулевого содержания в продукте исходного молибдена при неизменных параметрах разрядного контура и вольтамперных характеристиках дуги. Получение материала, состоящего из углерода и карбида молибдена, является важным результатом на пути к получению чистого карбида молибдена ввиду наличия известных в мире методов очистки подобных смесей. С другой стороны, наличие углеродных примесей в составе синтезируемого порошкового карбида молибдена в форме матрицы или оболочки частиц положительно сказывается на характеристиках катализатора, реализуемого на основе рассматриваемого материала $[10,11]$. Таким образом, фазовый состав продукта синтеза позволяет полагать возможным

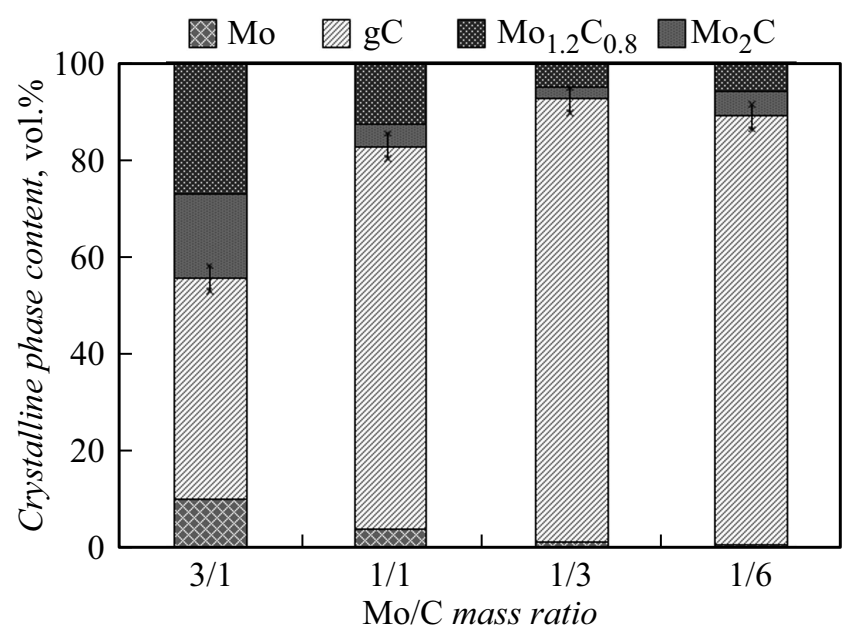

Рис. 2. Зависимость содержания кристаллических фаз в составе продукта синтеза от массового соотношения Мо/С в продукте. 


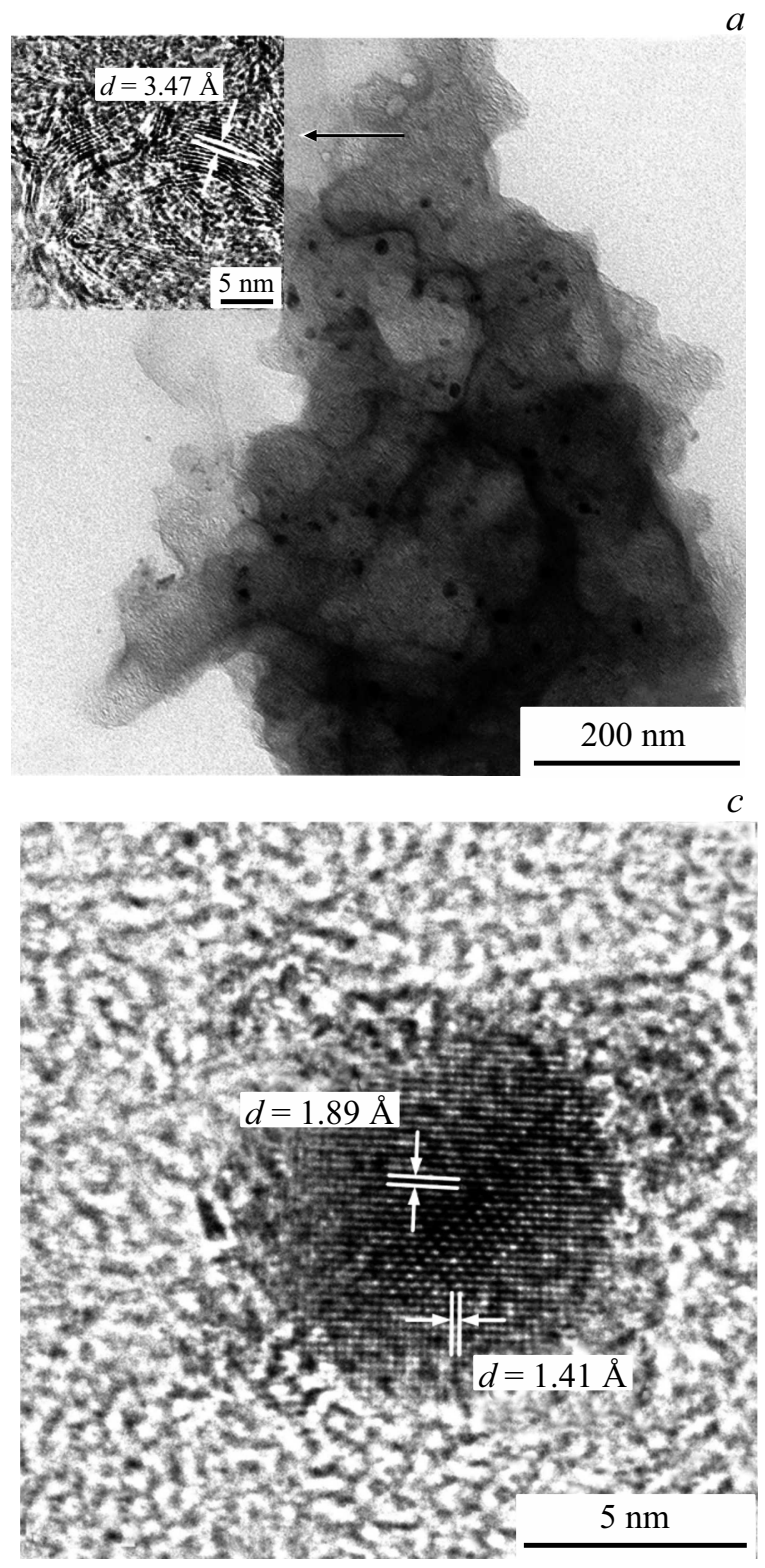

$a$
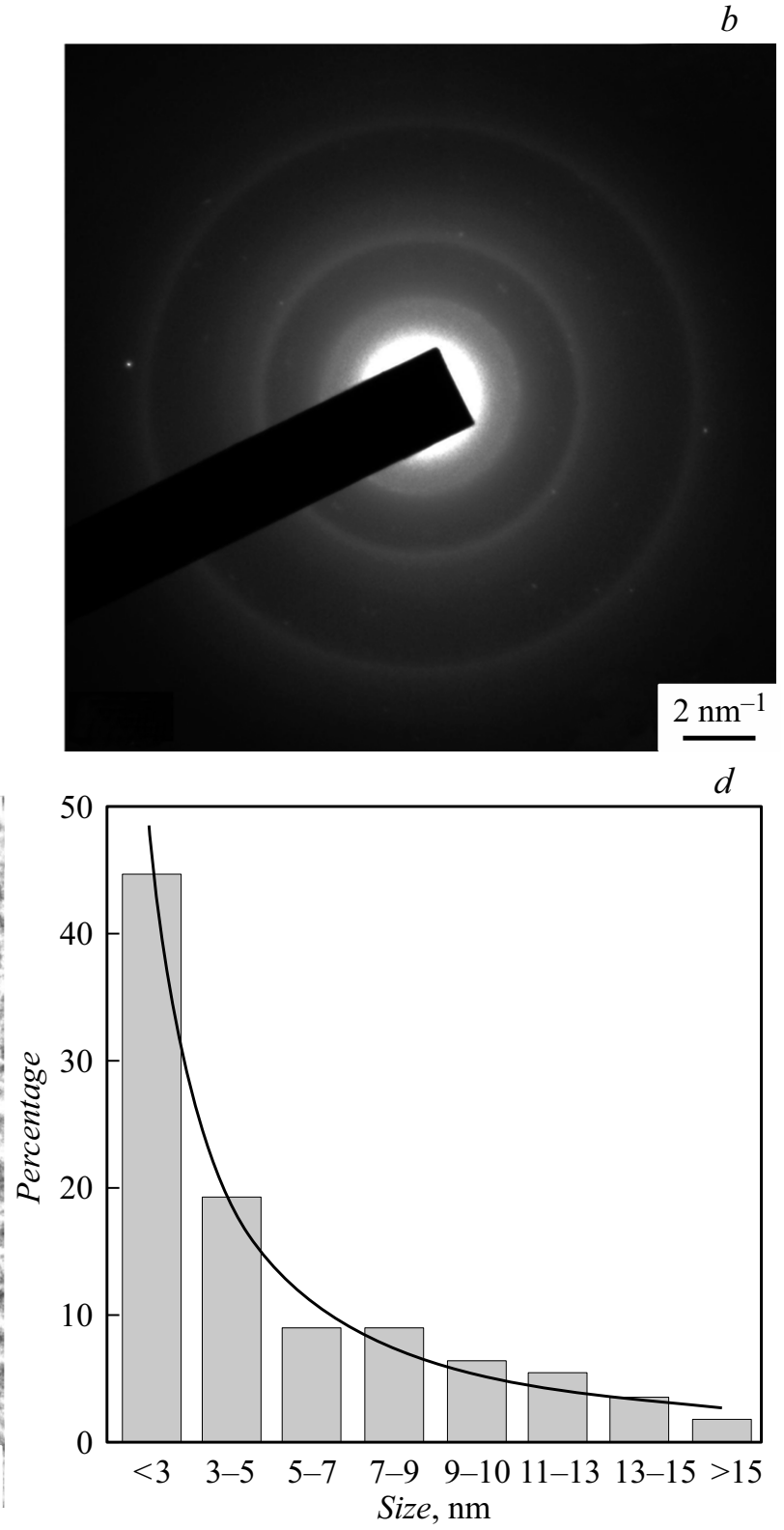

Pис. 3. Результаты просвечивающей электронной микроскопии: $a, c-$ светлопольные снимки высокого разрешения (НRTЕМснимки); $b-\mathrm{SAED}, d-$ распределение частиц карбида молибдена по размерам.

применение получаемого материала в составе катализаторов, а также выделение в будущем из его состава чистого карбида молибдена.

Согласно результатам энергодисперсионного анализа (по данным 30 измерений) полученных материалов на базе растрового электронного микроскопа, продукт преимушественно состоит из углерода и молибдена, может содержать примеси кислорода до $~ 6 \pm 1$ mass\%, других химических элементов (F, Na, $\mathrm{Al}, \mathrm{S}, \mathrm{Fe})$ с суммарным содержанием до $\sim 2$ mass $\%$. Наличие в продукте нескольких процентов кислорода (возможно, адсорбированного), а также других широко распространенных примесей представляется нормальным в силу несовершенства методов синтеза, хранения и обработки как ис- ходных реагентов, так и продукта синтеза, хранения порошков в воздушной среде. Изучение морфологических типов объектов микроразмерного диапазона в составе продукта является предметом отдельной публикации; в настоящей работе основное внимание сосредоточено на морфологии наноразмерной составляющей, выделенной из состава продукта посредством приготовления спиртовой суспензии и исследованной с помощью просвечивающего электронного микроскопа (рис. 3). Основную массу выделенной фракции составляет углеродная матрица, в которую погружены частицы со средним размером преимущественно до $\sim 5-10 \mathrm{~nm}$. Углеродной матрице на картине электронной дифракции (SAED) соответствуют три явно выраженных размытых коль- 
ца; частицам карбида молибдена отвечают отдельные дифракционные максимумы. Для удобства сравнения полученных экспериментально данных с эталонными составлена таблица. Видно, что все идентифицированные максимумы могут быть отнесены как минимум к одной из обозначенных фаз. Снимок в режиме прямого разрешения подтверждает принадлежность углеродной матрицы к структуре графита, так как определенная величина межплоскостного расстояния близка к типичной для данной фазы $(3.47 \AA)$. Также снимок в режиме прямого разрешения показывает наличие в структуре отдельных наноразмерных частиц межплоскостных расстояний $d=1.89$ и $1.41 \AA$, которые одновременно близки к межплоскостным расстояниям структур $\mathrm{Mo}_{2} \mathrm{C}$ и $\mathrm{Mo}_{1.2} \mathrm{C}_{0.8}$ и однозначно не соответствуют структуре кубического молибдена и графита. К сожалению, ввиду близости эталонных межплоскостных расстояний, особенностей образца и инструментальных ограничений микроскопа не удалось зафиксировать различия в морфологии частиц $\mathrm{Mo}_{2} \mathrm{C}$ и $\mathrm{Mo}_{1.2} \mathrm{C}_{0.8}$, однако исходя из совокупности приведенных данных можно однозначно утверждать, что рассматриваемые частицы в углеродной матрице являются карбидом молибдена.

На основе совокупности представленных данных можно сделать заключение о возможности получения наноразмерных частиц карбида молибдена в углеродной матрице безвакуумным электродуговым методом. При этом наличие в продукте синтеза одновременно более одной фазы карбида молибдена представляется вполне нормальным явлением [10], как и погружение частиц карбида молибдена в углеродную матрицу $[11,12]$. Формирование углеродной матрицы может быть объяснено избытком углерода в процессе синтеза согласно известной диаграмме состояний Мо-C [13] и является важной особенностью продукта синтеза, предотвращающей агломерацию частиц [14]. Согласно литературным данным, полученный материал со средним размером частиц карбида молибдена порядка $10 \mathrm{~nm}$ и менее может быть полезным в области создания катализаторов, характеризующихся высокой активностью, сравнимой с активностью платины [15].

\section{Финансирование работы}

Работа выполнена при поддержке гранта Президента РФ (МК-633.2019.8).

\section{Список литературы}

[1] Lin L., Zhou W., Gao R., Yao S., Zhang X., Xu W., Zheng S., Jiang Z., Yu Q., Li Y.-W., Shi C., Wen X.-D., Ma D. // Nature. 2017. V. 544. N 7648. P. 80-83. DOI: 10.1038/nature 21672

[2] Ma Y., Guan G., Hao X., Cao J., Abudula A. // Renewable Sustainable Energy Rev. 2017. V. 75. P. 1101-1129. https://doi.org/10.1016/j.rser.2016.11.092

[3] Dantas S.L.A., Lopes-Moriyama A.L., Sena M.S., Souza C.P. // Ceram. Int. 2018. V. 44. N 16. P. 20551-20555. DOI: $10.1016 /$ j.ceramint.2018.08.054
[4] Vitale G., Guzmán H., Frauwallner M.L., Scott C.E., PereiraAlmao P. // Catalys. Today. 2015. V. 250. P. 123-133. https://doi.org/10.1016/j.cattod.2014.05.011

[5] Saito Y., Matsumoto T., Nishikubo K. // J. Cryst. Growth. 1997. V. 172. N 1-2. P. 163-170. https://doi.org/10.1016/S0022-0248(96)00709-9

[6] Fu R.K.Y., Mei Y.F., Shen L.R., Siu G.G., Chu P.K., Cheung W.Y., Wong S.P. // Surf. Coat. Technol. 2004. V. 186. N 1. P. $112-117$. DOI: $10.1016 /$ j.surfcoat.2004.04.024

[7] Arora N., Sharma N.N. // Diamond Related Mater. 2014. V. 50. P. $135-150$. https://doi.org/10.1016/j.diamond.2014.10.001

[8] Su Y., Wei H., Li T., Geng H., Zhang Y. // Mater. Res. Bull. 2014. V. 50. P. 23-25. https://doi.org/10.1016/j.materresbull.2013.10.013

[9] Пак А.Я., Мамонтов Г.Я. // Письма в ЖТФ. 2018. Т. 44. B. 14. C. $26-33$. DOI: 10.21883 /PJTF.2018.14.46341.17056

[10] Huang Y., Wang C., Song H., Bao Y., Lei X. // Int. J. Hydrogen Energy. 2018. V. 43. N 28. P. 12610-12617. doi.org/10.1016/j.ijhydene.2018.03.233

[11] Wei H., Xi Q., Chen X., Guo D., Ding F., Yang Z., Wang S., Li J., Huang S. // Adv. Sci. 2018. V. 5. N 3. P. 1700733. DOI: $10.1002 /$ advs.201700733

[12] Baklanova O.N., Vasilevich A.V., Lavrenov A.V., Drozdov V.A., Muromtsev I.V., Arbuzov A.B., Trenikhin M.V., Sigaeva S.S., Temerev V.L., Gorbunova O.V., Likholobov V.A., Nizovskii A.I., Kalinkin A.V. // J. Alloys Compd. 2017. V. 698. P. 1018-1027. http://dx.doi.org/10.1016/j.jallcom.2016.12.186

[13] Guardia-Valenzuela J., Bertarelli A., Carra F., Mariani N., Bizzaro S., Arenal R. // Carbon. 2018. V. 135. P. 72-84. https://doi.org/10.1016/j.carbon.2018.04.010

[14] Madrigal-Camacho M., Vilchis-Nestor A.R., CamachoLópez M., Camacho-López M.A. // Diamond Related Mater. 2018. V. 82. P. $63-69$. https://doi.org/10.1016/j.diamond.2017.12.019

[15] Xia K., Guo J., Xuan C., Huang T., Deng Z., Chen L., Wang D. // Chin. Chem. Lett. 2019. V. 30. N 1. P. 192-196. https://doi.org/10.1016/j.cclet.2018.05.009 